Swinton saw clearly', but one which could only be solved by the close co-operation of a large band of research workers having at their disposal the facilities of a well-equipped research laboratory. The problem has been attacked during the last decade in many of the large industrial research laboratories in America, Germany and Great Britain, and the progress in many of these organizations has been roughly parallel, but it is fitting that Great Britain should be the first to inaugurate a public television service employing the system which was first outlined twenty-eight years ago by a distinguished British scientist.

\footnotetext{
1 NATURE, 78, 151 (June 18, 1908).

"Autobiographical and other Writings". A. A. Campbell Swinton, pp. 131-137. (Longmans, Green and Co., Ltd.)

3 NATURE, 13\%, 984 (June 13, 1936).

- J. Rontgen Soc, Jan. 1912, p. 7

- NATURE, 78, 105 (June 4, 1908)

" "Autoblographical and other Writings". A. A. Campbell Swinton, p. 137 .

WiTURE, 118, 590 (Oct. 23, 1926).

- Wireless World, 14, 118 (1924).
}

\title{
Stratosphere Flight
}

$\mathrm{T}^{\mathrm{n}}$ HE recent world's height record, for aeroplanes, of $49,967 \mathrm{ft}$., set up by Squadron. Leader F. R. D. Swain, R.A.F., piloting a Bristol monoplane fitted with a special type Bristol Pegasus engine, has served to focus a certain attention upon the question of flights at great altitudes, and the possible advantages to be derived therefrom.

The most obvious gain comes from the reduction of the resistance to the aircraft's motion as the density of the air to be displaced decreases, which, if other conditions remained the same, would result in increases of speed of a valuable order. For example, in round figures, an aeroplane of maximum speed 180 miles per hour at sea-level would travel at 550 miles per hour at a height of a little more than ten miles. This is equivalent to London to New York (3,000 miles) in $5 \frac{1}{2}$ hours, neglecting the time taken to climb to and descend from that altitude.

Other probable advantages are a relative wind in a direction opposite to the rotation of the earth, if a shear effect in the belt of atmosphere rotating with the earth may be assumed; the absence of meteorological and electrical disturbances with their effect upon accurate navigation, that would also allow routes to follow the shortest line from point to point irrespective of the conditions upon the earth's surface, as for example across the polar regions; and the psychological effect of constant sunshine, lack of clouds and equable temperature conditions are possibly not to be ignored.

The principles upon which the flight of the present-day heavier-than-air machine are based, however, make use of the density of the atmosphere in several ways in which its rarefaction at great heights would be a definite disadvantage, and may possibly set a limit upon entering the stratosphere which will make it not worth while, at least as a commercial transport proposition. The importance of doing so for the purpose of research into the physical conditions comes within a different category.

The power plant gives the machine a forward motion through the medium of an airscrew, this being required in order that the circulation of air around the lifting surfaces may be set up, resulting in the necessary lift and control. A reduction in air density will lessen this thrust and thus reduce the lift indirectly by reducing the speed, in addition to the direct loss of lift. Further, use of full power would result in excessive rotational speed of the airscrew due to the thinness of the air. Variable pitch propellers, already a practicable proposition to a limited extent, will help in this respect.

The internal combustion engine, the present-day power plant, requires a definite weight of oxygen for the proper combustion of its fuel. The rarefied and poor quality air can be forced into the engine, up to a certain limit, by super-chargers, and after this it does not appear to be impossible to carry a supply of oxygen under pressure to make up this deficiency, more especially as a supply will probably have to be carried for the occupants of the aeroplane. The physiological requirements of the passengers and crew will call for extra size and weight of the cabin, which will have to be of sufficient capacity for the required change of air, to carry apparatus for storing the oxygen and for absorption of the carbon dioxide and moisture exhaled, and will almost certainly have to be heat insulated. This may be against the low temperature of the surrounding atmosphere, or against heat generated by the friction set up by the rubbing of the air at these high speeds. Which will predominate, and how far one will balance the other, will depend upon the heights and speeds attained.

This state of affairs is already partly achieved, and its consummation does not appear to be beyond the bounds of possibility, at least, as a scientific experiment. As an everyday transport 
proposition, experiment alone can settle whether the balance between total loads carried, and the part left for useful carrying capacity, after the elaborate equipment is installed, and the effect of the artificial conditions, accelerations and such discomforts upon the passengers, will make it worth while. It has been suggested that under these conditions, and with existing materials and aerodynamic design as now accepted, there are theoretical reasons for thinking that a limit will occur upon speeds at about 650 miles per hour.

To travel without this limit in the higher regions of the stratosphere will necessitate the use of some new method of propulsion, not dependent upon the presence of air for its functioning or the application of its tractive effort. The obvious solution that comes to the mind in this case is rocket propulsion. A certain amount of experiment has already been carried out in this respect; one quite serious proposal was made not long ago to fire mails from France to England across the Straits of Dover. The principal problem to be solved is that of control of the orientation of the machine while in flight. If this calls for the presence of the human element, the effect of the terrific accelerations at the start and finish cannot be ignored. Should this prove insuperable, automatic control of some kind does not appear impossible, but it will necessarily exclude passenger traffic.
A possible midway step between the two that has often been suggested is reported to be under construction and nearing completion in Soviet Russia. An aeroplane fitted with the usual internal combustion engine and propeller also carries rocket tubes. These will continue to give the necessary forward movement by reaction propulsion after the normal tractive effort has become negligible by reason of the reduction of the density of the air. This is not the complete rocket propulsion, and its efficiency would still appear to be largely dependent upon the air density for its reactive effort.

With regard to flight in the stratosphere by lighter-than-air craft, this is a much simpler problem. It becomes a matter of calculation as to the displacements of the balloon at the anticipated air density at the maximum height proposed, and the design of the envelope and the passengers' car to withstand the pressure differences. Such flights are of importance for the investigation of conditions in the upper air, and the perfection of such meteorological information will be of importance in the development of heavier-than-air craft under similar conditions. There does not appear to be any direct value in them from the point of view of controlled air travel. The height record for free balloon travel in the stratosphere is $72,395 \mathrm{ft}$., reached by Captains Stevens and Anderson, United States Air Corps, in the balloon Explorer II on November 11, 1935.

\section{Obituary}

Mr. J. W. Gordon, K.C.

$\mathrm{M}^{\mathrm{s}}$ R. JOHN WILLIAM GORDON, K.C., who died in his eighty-third year on September 21 last, was the son of Mr. John Lewis Gordon, and was called to the Bar in 1884. He was a well-known Patent Law expert and was always strongly attracted to scientific and technical investigations. He was a member of the Commission appointed to inquire into the pitch industry of Trinidad; assisted in drafting the Patent Act of 1907 ; was formerly honorary secretary of the Royal Microscopical Society; received the gold medal of the Society of Engineers for his work on railway surveying by photography; and throughout his long life he never lost his interest in optical and allied subjects. It is, perhaps, by his work in connexion with microscopic resolution that he will be best remembered in the future.

Mr. Gordon also did some interesting and valuable work with regard to the plotting of surveys from airphotographs, and in his book "Generalised Linear Perspective", which was published in 1922, he describes how he rediscovered a method originally devised by Brook Taylor (of Taylor's theorem) two hundred years ago. Briefly, the method is this; if there are three points in a line in the cartographic field and the real lengths of the two segments are known, then it is easy to calculate the position of the point where the given line cuts the horizon; and if there is available a second similarly divided line, the horizon can be drawn.

The system is essentially a point-by-point method of plotting, and there are cases in which it may be of value, especially when the photographic plate is considerably tilted. But Mr. Gordon was inclined to claim somewhat too much for this method, which, after all, is only one of many. Nowadays we are in the more intricate region of stereoscopic air-photography and of mechanical plotters, and, except in very simple cases, we have left point-by-point methods behind us. But Mr. Gordon's book has its own place in the history of the subject, and perhaps that is as much as it will be possible to say of the writings of most of us. 